\title{
A comprehensive systematic review of stakeholder attitudes to alternatives to prospective informed consent in paediatric acute care research
}

Jeremy Furyk ${ }^{1,2^{*}}$ D, Kris McBain-Rigg ${ }^{1}$, Bronia Renison ${ }^{3}$, Kerrianne Watt $^{4}$, Richard Franklin ${ }^{1}$, Theophilus I. Emeto ${ }^{1}$, Robin A. Ray ${ }^{5}$, Franz E. Babl $\left.\right|^{6,7,8}$ and Stuart Dalziel ${ }^{9}$

\begin{abstract}
Background: A challenge of performing research in the paediatric emergency and acute care setting is obtaining valid prospective informed consent from parents. The ethical issues are complex, and it is important to consider the perspective of participants, health care workers and researchers on research without prospective informed consent while planning this type of research.

Methods: We performed a systematic review according to PRISMA guidelines, of empirical evidence relating to the process, experiences and acceptability of alternatives to prospective informed consent, in the paediatric emergency or acute care setting. Major medical databases and grey sources were searched and results were screened and assessed against eligibility criteria by 2 authors, and full text articles of relevant studies obtained. Data were extracted onto data collection forms and imported into data management software for analysis.

Results: Thirteen studies were included in the review consisting of nine full text articles and four abstracts. Given the heterogeneity of the methods, results could not be quantitatively combined for meta-analysis, and qualitative results are presented in narrative form, according to themes identified from the data. Major themes include capacity of parents to provide informed consent, feasibility of informed consent, support for alternatives to informed consent, process issues, modified consent process, child death, and community consultation.

Conclusion: Our review demonstrated that children, their families, and health care staff recognise the requirement for research without prior consent, and are generally supportive of enrolling children in such research with the provisions of limiting risk, and informing parents as soon as possible. Australian data and perspectives of children are lacking and represent important knowledge gaps.
\end{abstract}

Keywords: Consent, Paediatrics, Emergency care

\section{Background}

There is a community expectation that children presenting to emergency departments (ED) and acute care settings receive the best possible care based on high-level evidence. The reality though is many treatment decisions are not evidence based, but rather based on theoretical

\footnotetext{
* Correspondence: Jeremy.Furyk@barwonhealth.org.au

${ }^{1}$ College of Public Health, Medical and Veterinary Sciences, James Cook University, Townsville, QLD 4814, Australia

${ }^{2}$ University Hospital Geelong, Geelong, Victoria, Australia

Full list of author information is available at the end of the article
}

considerations, simply reflecting "what we have always done" or extrapolated from adult data $[1,2]$. This is inappropriate as children differ from adults both anatomically and physiologically and health conditions may be entirely unique to the paediatric population [3]. Clinical research in children is necessary for paediatric emergency medicine to advance.

The ethical issues involved in the conduct of paediatric clinical research are complex and are compounded in time critical and life threatening situations in emergency care. The guiding principles of conducting ethical research are:

(c) The Author(s). 2018 Open Access This article is distributed under the terms of the Creative Commons Attribution 4.0 International License (http://creativecommons.org/licenses/by/4.0/), which permits unrestricted use, distribution, and reproduction in any medium, provided you give appropriate credit to the original author(s) and the source, provide a link to the Creative Commons license, and indicate if changes were made. The Creative Commons Public Domain Dedication waiver (http://creativecommons.org/publicdomain/zero/1.0/) applies to the data made available in this article, unless otherwise stated. 
respect for autonomy, beneficence and justice [4]. Respect for autonomy is usually reflected in obtaining informed consent from participants, which remains a fundamental principle in the protection of human participants in medical research. When the participant is a child, consent must usually be obtained from a parent or proxy. While proposing to conduct research without informed consent may seem to contravene the ethical principle of respect for autonomy, denying participation in research to those unable to consent contravenes the ethical principle of justice, meaning fair distribution to the benefits of research participation and fair access to the benefits of research $[4,5]$.

Children are usually considered a "vulnerable" group in terms of participation in research due to their inability to consent and potential for exploitation [4]. While not without controversy, emergency research without consent has been performed in adults for some time; it is relatively less established in paediatric emergency and critical care. Emergency patients themselves are often considered a vulnerable group, given their reliance on the care being offered [6]. Thus research conducted on children in the emergency setting leaves participants vulnerable on multiple counts.

Performing clinical research in emergency settings is difficult. The environment is often chaotic and unpredictable, presentations of interest may be rare in individual institutions, staff are often stretched with clinical responsibilities, and interventions may have a narrow therapeutic window. One of the many challenges researchers face in conducting research in the ED and other acute care settings is the difficulty of obtaining prospective informed consent [7-9]. Valid prospective informed consent requires provision and comprehension of information about the purpose, methods, demands, risks, inconveniences, discomforts and possible outcomes of the research [4]. In Australia this assumes the capacity for decision-making, a free and voluntary process including adequate disclosure regarding the act performed. Several of these components may not be possible in time critical situations in the acute care setting and there may be an argument for a waiver of informed consent, retrospective or deferred consent. A waiver of informed consent refers to research that has ethical approval to proceed without the requirement for participant or proxy informed consent. Deferred or retrospective consent describes a process where participants are enrolled without informed consent, followed by requesting permission to continue in the study, or if the study intervention has ended, permission to use the data [1].

Guiding principles for use of alternatives to prospective informed consent in emergency research are outlined in the Declaration of Helsinki; "if the research cannot be delayed, the study may proceed without informed consent provided that the specific reasons for involving subjects with a condition that renders them unable to give informed consent have been stated in the research protocol and the study has been approved by a research ethics committee. Consent to remain in the research should be obtained as soon as possible from the subject or a legally authorized representative" [10]. These principles are further reiterated in local documents such as the National Health and Medical Research Council (NHMRC) National Statement on ethical conduct in human research, which allows consent to occur after an intervention if consent is not practicable, there is potential benefit to the child, risk is low, the research has merit and there is no reason to suspect the parents would not give consent. Similar requirements exist in New Zealand [6], the United Kingdom (UK) [11], and the United States of America (USA) [12]. Although implementation is variable, and specific requirements differ internationally, most require the research to be "therapeutic" rather than "non-therapeutic", offering potential benefit to the participant and pose no more than "minimal risk" $[7,13]$.

The ethical issues of paediatric acute care research are complex. Even if the therapeutic window of the intervention allows an informed consent discussion and a proxy is immediately available, parents may not have capacity to undertake such decisions. There may be the perception of coercion to participate in research by parents who are dependent on receiving emergency care for their children. Locally, ethics guidance documents such as the NHMRC national statement lack clarity regarding specific requirements for research in these circumstances, and are variably interpreted by ethics committees. There is a paucity of evidence of the acceptability of research without prospective informed consent in paediatric acute care. It is important to explore and understand the perceptions and experiences of parents, health care workers and researchers to alternatives to prospective informed consent in paediatric acute care and emergency research to inform the design of future research and guidance documents.

\section{Aim/objective}

This paper aims to review and synthesize the available empiric evidence with regard to alternatives to prospective informed consent in the context of paediatric acute care research from the perspective of the children, their families, health care staff, institutions, and the community.

\section{Methods}

We performed a comprehensive systematic review according to the Preferred Reporting Items for Systematic Reviews and Meta-Analysis (PRISMA) guideline [14]. 


\section{Search strategy}

The literature search was designed in conjunction with a medical librarian (BR) and included major databases: Medline (Ovid), Embase (Ovid), Web of Science, CINAHL, and PsycINFO. No limits were set with regard to language or date restriction. See Additional file 1 for Medline (Ovid) search strategy. The electronic database search was run in April 2017 and updated in Jan 2018.

The database search was supplemented by a Google Scholar search using the "cited by" feature, and a grey literature search including conference proceedings, government reports, raw data, theses and dissertations using the key words identified for searching medical databases. Conference abstracts of key recent emergency medicine meetings were hand searched for additional studies. A manual search was conducted of reference lists from identified articles.

\section{Registration}

The review was prospectively registered on the PROSPERO registry for systematic reviews. (PROSPERO 2016 CRD42016053963).

\section{Study selection}

Studies identified by the search strategy were exported into an EndNote library and duplicates removed. Title and abstracts were reviewed independently by two authors (JF and $\mathrm{KM}$ ), and assessed against eligibility criteria. Disputes were resolved with discussion, and adjudication by a third author (RR).

\section{Inclusion/exclusion criteria}

All study types (quantitative, qualitative and mixed methods) reporting original, empirical evidence relating to the process, experiences and acceptability of alternatives to prospective informed consent, in the paediatric, emergency or acute care setting were included. Perspectives of participants, parents or caregivers, clinicians, researchers and other staff were considered relevant. Studies reported in abstract only were considered. Studies conducted in the pre-hospital environment, emergency department and intensive care unit within all cultural and geographical contexts were included.

Studies that did not present original data e.g. reviews, commentaries, editorials, opinion pieces and letters to the editor were excluded. Studies conducted in the Neonatal Intensive Care Unit were excluded, as these units have their own unique clinical and ethical considerations, which were beyond the scope of this review. Studies only reporting adult patient data, or if paediatric subgroups were not reported separately, were excluded. Quality assessment was performed and reported; however study quality was not a selection criterion.

\section{Data extraction}

Data extraction was performed independently by two authors (JF and KM), and consisted of demographic details of the population studied, phenomenon of interest, methods used, main findings, and conclusions of the authors etc. Data extraction was an iterative process, and new emerging themes were crosschecked with primary articles.

\section{Data analysis and synthesis}

Identified full text studies and data extraction forms were imported into NVivo 11 for Mac for analysis (NVivo qualitative data analysis Software, QSR International Pty Ltd., version 11.1: 2016). We used an inclusive approach to data extraction, with all potentially relevant data included in the synthesis. Text from primary articles was coded into themes using the software. Primary themes identified from general background literature and reviews on alternatives to informed consent from adult literature formed the baseline analysis, and new themes iteratively added during analysis. The validity of the data extraction was reviewed by other authors (KW, RR, TIE).

We used thematic synthesis to synthesize results of our review, which involved free coding of textual data from primary studies, organization into descriptive themes, and generation of analytical themes producing a new interpretation. This technique is similar to metaethnography and grounded theory and is useful when drawing together common elements in heterogeneous studies $[15,16]$.

\section{Critical appraisal of included studies}

Quantitative observational studies were assessed using the "Quality Assessment Tool for Observational Cohort and Cross-Sectional Studies" from the National Heart, Lung and Blood Institute [17]. For qualitative studies we used the "Qualitative Assessment and Review Instrument" (QARI) developed by the Joanna Briggs Institute [18]. The assessment was made by two authors independently (JF and KM), by extracting the relevant text from the publication that addressed the quality assessment criteria, and assigning each question yes, no, unclear or not applicable as to whether quality criteria was met. Disagreements were resolved by consensus or by consulting with third author (RR).

Studies were not excluded on the basis of this assessment as there is no empirically tested method of exclusion of such studies on the basis of quality. Sensitivity analysis was performed excluding studies globally assessed as "poor quality" to determine to what extent exclusion of these studies affected the review e.g. if excluding themes generated from the original synthesis affects the "thickness" of detail in the synthesis. 


\section{Rigor}

Methodological quality was ensured by a process coding by multiple authors and triangulation with disputes resolved by consensus.

\section{Results}

The search identified 443 studies (CINAHL 30, Embase (Ovid) 227, Medline (Ovid) 156, PsycINFO (Ovid) 9, Web of Science (21), leaving 295 after removal of duplicates. An additional 12 articles were identified from other sources including reference lists, cite feature and Google scholar. A review of titles and abstracts resulted in 37 articles for full text review. Of these 24 studies were excluded, five studies published as abstracts were duplications of subsequently published full text articles, five abstracts and 14 other studies were excluded as they did not meet inclusion criteria. This is summarised in Fig. 1. Thirteen studies were included in the review consisting of nine full text articles and four abstracts.

Characteristics of included studies are summarised in Tables 1. Critical appraisal of included articles is summarised in Tables 2 and 3. Critical appraisal of the four studies included in abstract form was not possible. Given the heterogeneity of the methods, results could not be quantitatively combined for meta-analysis. Qualitative results are presented in narrative form, according to themes identified from the data.

\section{Capacity of parents or guardians to provide prospective informed consent}

The capacity of the consenting individual is a critical requirement to providing valid prospective informed consent. Five quantitative, mixed methods and qualitative studies have provided data on capacity of parents to provide informed consent in the context of emergency and critical care research [19-23].

Practitioners' perspectives on parental capacity to provide prospective informed consent for a child in the context of emergency and critical care research indicated a divergence of views, largely regarding the ability of laypeople to process and comprehend information at a highly stressful time such as an emergency event [19, 21-23]. Practitioners across the included literature generally reported that parents had a diminished ability to process information and comprehend trial information, especially in the acute stages of a child's presentation [19, 21-23], and

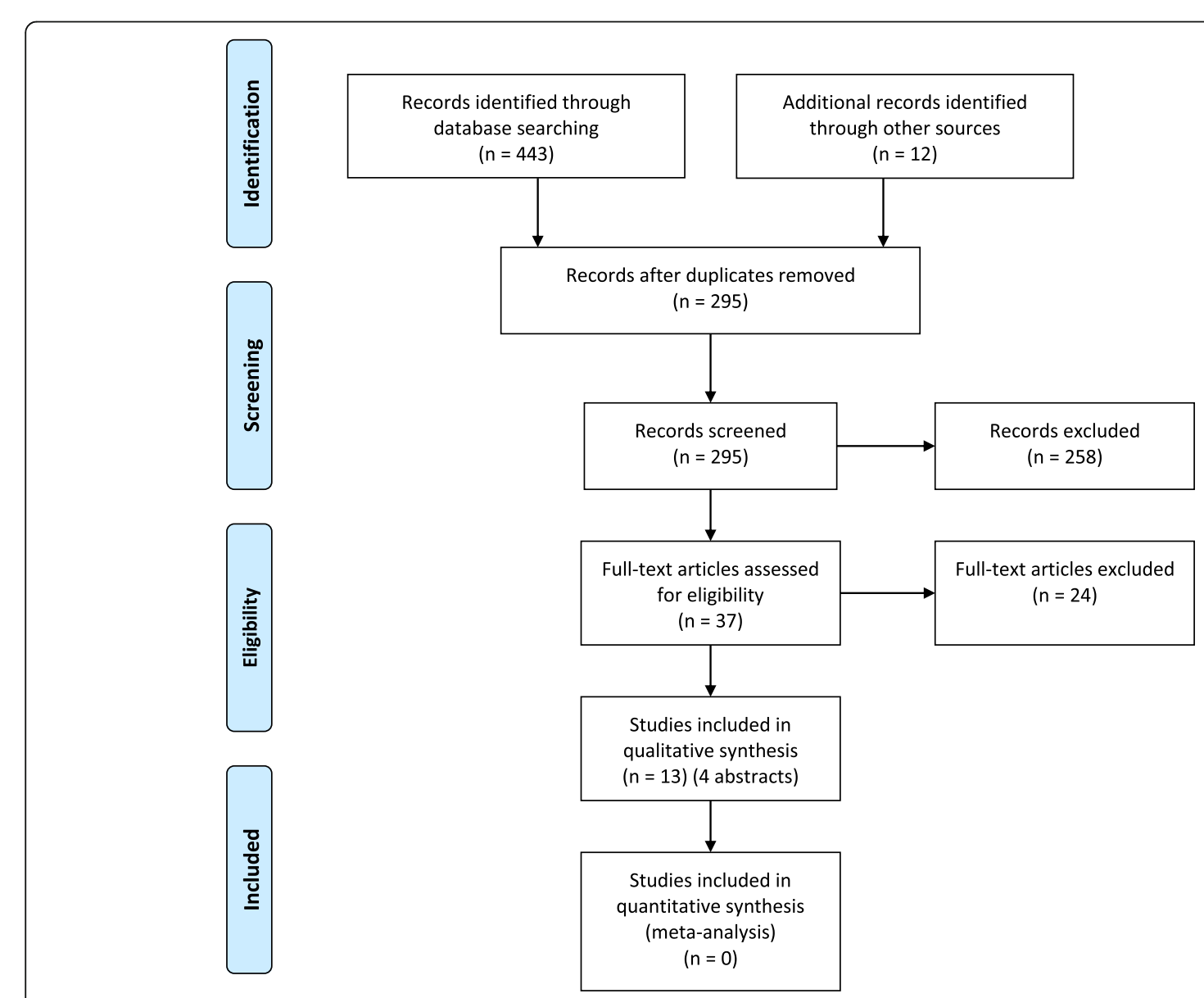

Fig. 1 PRISMA flow diagram 


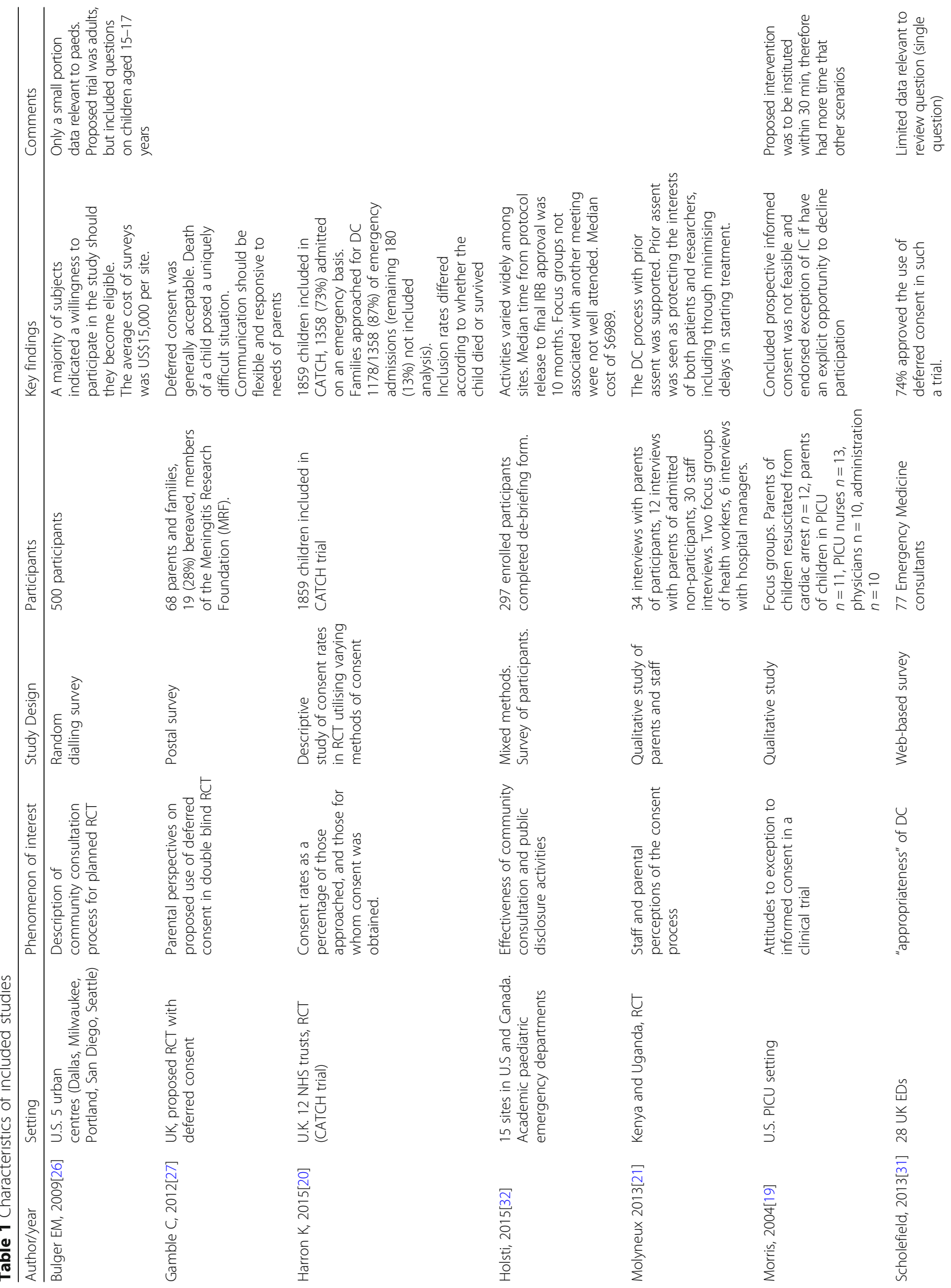




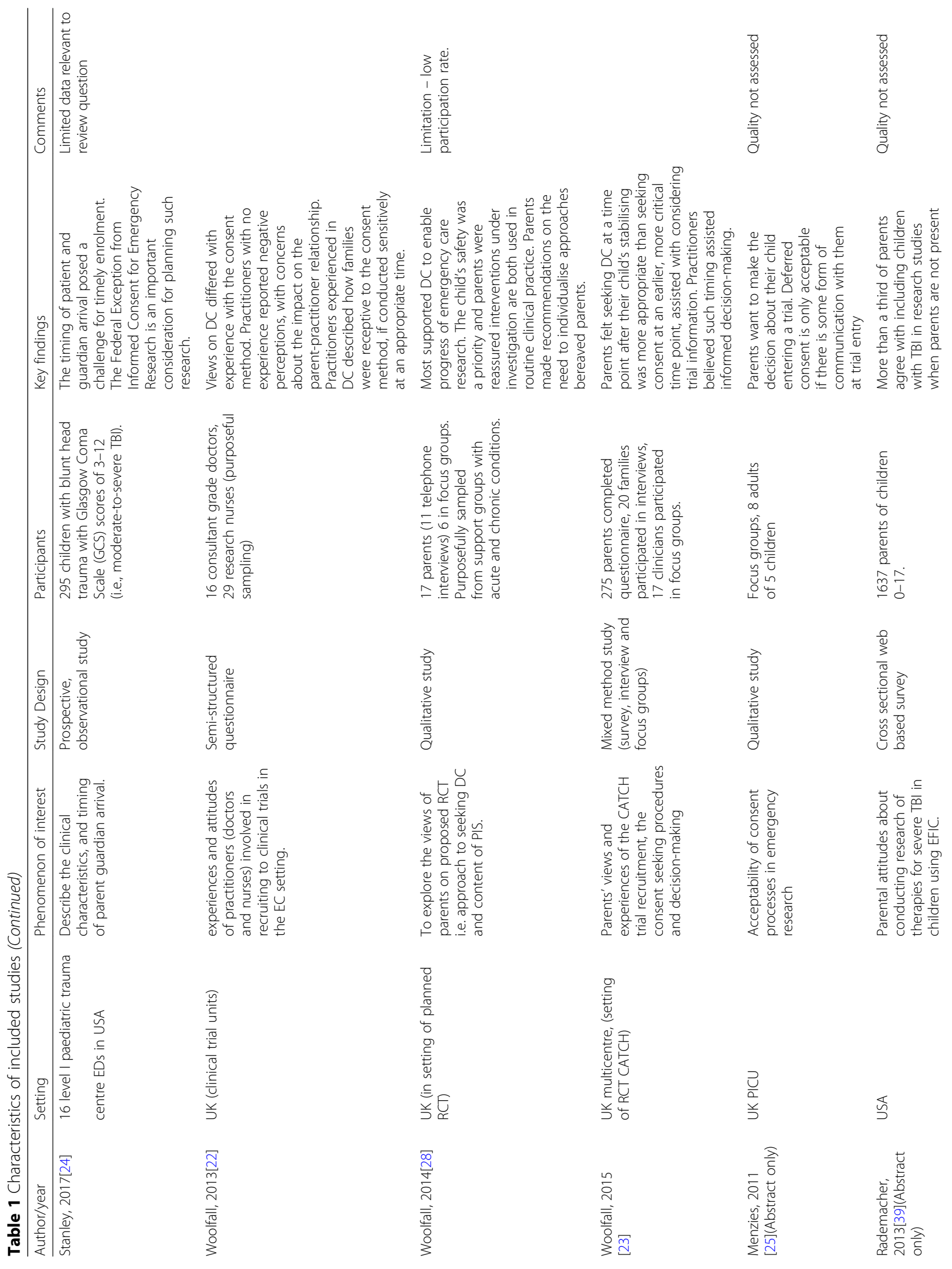


Furyk et al. BMC Medical Ethics (2018) 19:89

Page 7 of 14

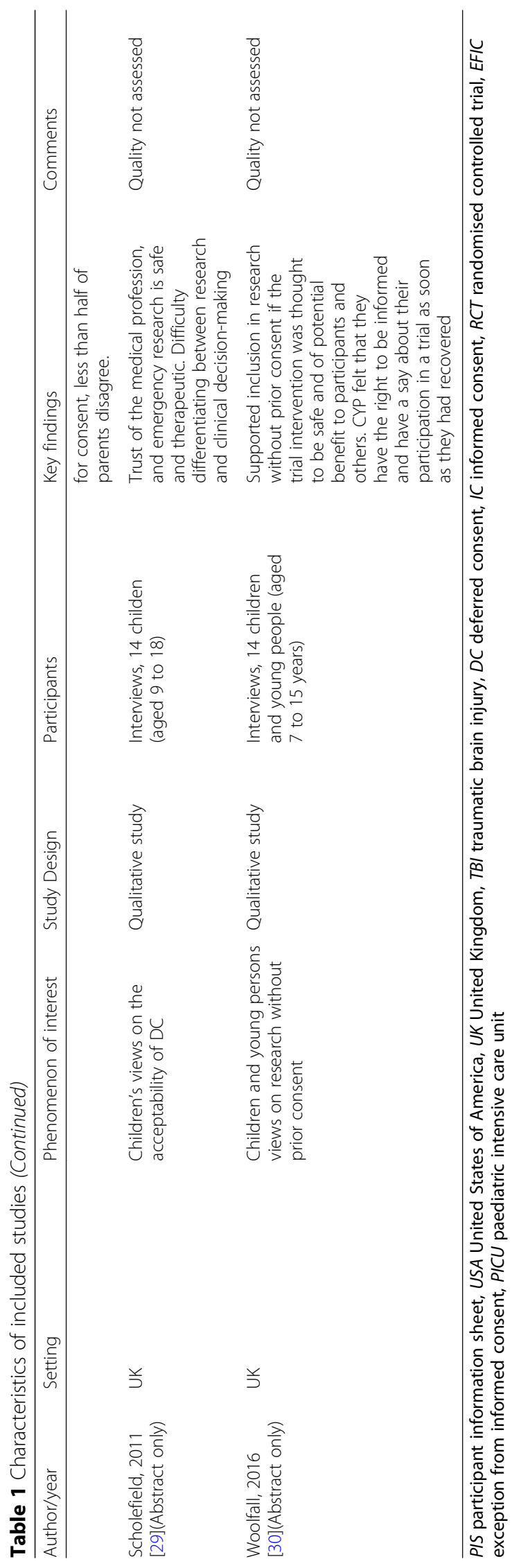


Table 2 Critical appraisal of qualitative studies

\begin{tabular}{|c|c|c|c|c|c|}
\hline & $\begin{array}{l}\widetilde{N} \\
\text { N } \\
\frac{0}{0} \\
\bar{E} \\
\mathbb{0}\end{array}$ & 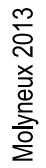 & 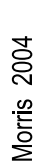 & 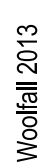 & 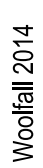 \\
\hline $\begin{array}{l}\text { 1. There is congruity between the stated philosophical perspective and the } \\
\text { research methodology }\end{array}$ & & & & & \\
\hline $\begin{array}{l}\text { 2. There is congruity between the research methodology and the research } \\
\text { question or objectives. }\end{array}$ & & & & & \\
\hline $\begin{array}{l}\text { 3. There is congruity between the research methodology and the methods } \\
\text { used to collect data. }\end{array}$ & & & & & \\
\hline $\begin{array}{l}\text { 4. There is congruity between the research methodology and the } \\
\text { representation and analysis of data. }\end{array}$ & & & & & \\
\hline $\begin{array}{l}\text { 5. There is congruity between the research methodology and interpretation } \\
\text { of results. }\end{array}$ & & & & & \\
\hline 6. There is a statement locating the researcher culturally or theoretically. & & & & & \\
\hline $\begin{array}{l}\text { 7. The influence of the researcher on the research, and vice-versa, is } \\
\text { addressed }\end{array}$ & & & & & \\
\hline 8. Participants, and their voices, are adequately represented. & & & & & \\
\hline $\begin{array}{l}\text { 9. The research is ethical according to current criteria or, for recent studies, } \\
\text { there is evidence of ethical approval by an appropriate body. }\end{array}$ & & & & & \\
\hline $\begin{array}{l}\text { 10. Conclusions drawn in the research report do appear to flow from the } \\
\text { analysis, or interpretation, of the data. }\end{array}$ & & & & & \\
\hline
\end{tabular}

Criteria met, Criteria not met, unclear or not applicable

Table 3 Critical appraisal of quantitative studies

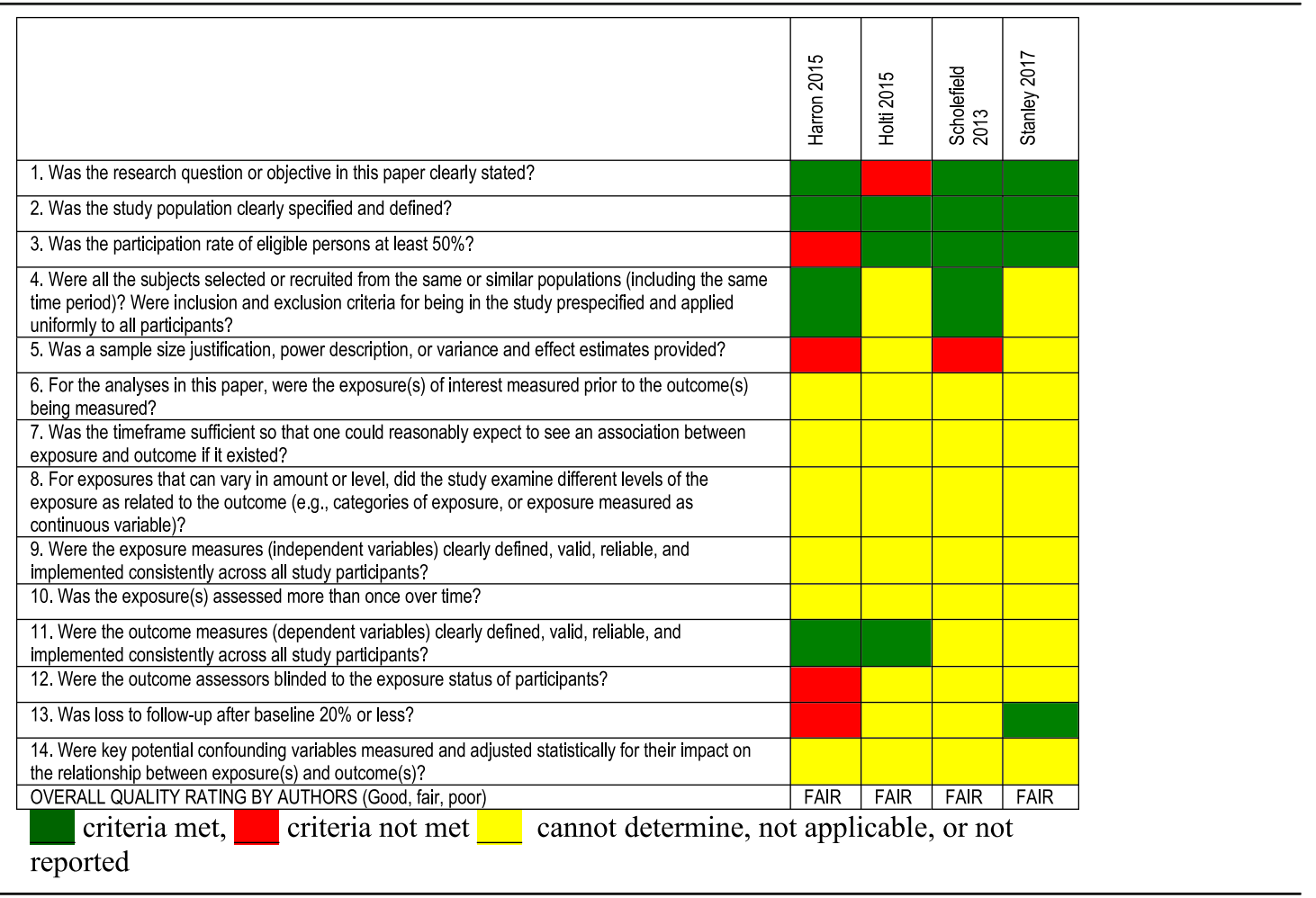


that meaningful consent in these circumstances was not possible [19]. Harron et al., found that some participants were not approached for deferred consent after randomization as research staff were concerned that they were "not in the right state of mind" [20]. However, this view was not universal, as in a study by Woolfall et al. 26/ 45 practitioners believed parents understood trial information provided in an emergency situation "well" or "very well", with about one third of those surveyed remaining undecided [22].

Parental perspectives on capacity to provide informed consent were similar to those of practitioners, in terms of diminished ability to process and comprehend information in the face of high stress during the acute care stages of presentation [19, 21, 22]. Supporting this, in a study where deferred or retrospective consent was obtained, parents demonstrated relatively poor comprehension of important research elements and almost a quarter described their experience as clinical care [21].

\section{Feasibility of prospective informed consent}

Two studies specifically addressed whether prospective informed consent was feasible [19, 24]. A study conducted by the Pediatric Emergency Care Applied Research Network (PECARN), exploring the feasibility of various aspects of a study of moderate to severe traumatic brain injury, found that parents and guardians are often not available within the narrow therapeutic window of investigational therapies [24]. While children often arrived within an hour or two of injury, most parents and guardians did not arrive until 2 to $3 \mathrm{~h}$ or later. This was more apparent for children transferred from another site and more severely injured children. The authors concluded that an exception of informed consent would be necessary for timely enrolment of children into such a trial [24]. A qualitative study using focus groups of parents and staff of a paediatric intensive care setting to discuss a cardiac arrest research scenario, concluded that meaningful prospective informed consent was not feasible, and endorsed exception of informed consent, with the proviso that parents were offered an opportunity to decline participation prior to enrolment [19].

\section{Support for alternatives to prospective informed consent}

Estimates of support for research with alternatives to informed consent are broad and generally influenced by a number of factors. Five included studies were performed as part of a community consultation process, which is a federal requirement in the USA for research performed under a waiver of informed consent [12], and used in other settings as well $[21,25]$. These studies have quantified the level of support; however combining these estimates is inappropriate because of the heterogeneity of methods used and the specific contexts of the individual studies. Community consultation has included perspectives of both the parents of prospective participants, as well as health professionals.

A random dialling phone survey of over 2000 participants, for an out of hospital resuscitation study conducted in 5 states in the USA explored support for the exception to written consent in both adult participants and the 15-17 year old subgroup of the trial [26]. The study found $42.7-71.0 \%$ supported the exception to written consent being justified for 15-17 year olds, and in the best interests of the patients and the community which was only slightly lower than support for adults in the same trial [26]. Similar support has been reported in a UK study of parents of children who had suffered bacterial meningitis or meningococcal septicaemia, including bereaved parents [27]. In a postal survey 45/66 (68\%) indicated they would be willing for their child to be included in a trial without the trial being explained beforehand [27]. In a study of inpatient resuscitation research, more than $60 \%$ of parents were supportive of the study procedures including the exception to prospective informed consent [19].

In qualitative studies parents were generally supportive of research without prior consent [28], with reasons including altruism and general trust in the medical profession to make appropriate decisions [23, 27-30]. However, this sentiment was often accompanied by reservations about the level of risk or potential for harm of the intervention, or as dependent on the type of study being performed [23, 28]. A common theme was the importance to prioritise the management of the child prior to detailed explanations or excessive paperwork [23]. Some parents' support for research without prospective consent was contingent on the child's outcome [19, 28]. Such reservations led to an emphasis on the importance of appropriate explanations regarding the necessity for a deferred consent process in these research settings [28].

While the majority of studies have demonstrated that most parents understand and support the concept, some individuals hold strongly opposing views about research without prior consent, taking the perspective that a child should not be exposed to research without prior consent, and parents must be consulted before children are enrolled [23, 27]. Common reasons for opposing research without consent include the fear of adverse effects and feelings that the parents should "not lose the right to consent" [26].

The health professionals' perspective varied in terms of support for research without prior consent. USA researchers found only $50 \%$ of staff supported a trial with exception to informed consent. However a large proportion were neutral (38\%) and only $12 \%$ opposed the planned trial procedures [19]. In the UK, a survey of emergency medicine consultants found that $34 / 46$ (74\%) 
believed deferred consent would be acceptable for a planned trial evaluating therapeutic hypothermia following a paediatric cardiac arrest [31]. Qualitative studies have explored reasoning behind divergent views regarding research without prospective informed consent [19, 22, 23, 28]. Practitioners and researchers enrolling children in studies suggested familiarity with using a deferred consent process influenced acceptability and level of comfort of the procedure. Practitioners and researchers who had previous experience of the deferred consent method generally reported families as being receptive to the method if handled sensitively [22].

Only two identified studies reported the opinions of children on research without prior consent, and both were available in abstract form only [29,30]. Children in these studies generally regarded the use of exception from informed consent as acceptable [29], especially in life threatening situations [30].

\section{Community consultation}

Two studies explored other issues around community consultation including cost, value and variability in implementation [26, 32]. Requirements of community consultation are at the discretion of local institutional review boards (IRBs) and variability in requirements was evident, particularly when involving multiple centres and different jurisdictions [26, 32]. Methods of community consultation included focus groups, interviews, surveys, town meetings, and public disclosure involving news releases, mailings and public service announcements. Another study with various modalities found focus groups were not well attended, with a quarter having no attendees. Only $5 \%$ of research participants had heard about the trial from community consultation and public disclosure activities [32]. The cost of community consultation was reported in two studies. The phone surveys conducted by one large multicentre study averaged US $\$ 15,000$ per site [26]. Another study utilising various modalities calculated the median cost of activities was about US $\$ 7000$ [32]. The median additional time of this process was 10 months.

\section{Process issues}

Parents commented on the amount of information provided on consent forms as an issue in decision making $[23,28]$. When the child was ill, parents prioritised the treatment of the child over consent procedures, and preferred simple clear information on a single page [23].

A process of pre-consent was considered in two studies where potential participants are given the opportunity to consent or opt-out of participating in a trial, before they meet eligibility criteria, typically in an at risk population $[19,32]$. In a study of paediatric status epilepticus, over 4000 patients considered at risk of prolonged seizures received information about the trial, but only 6 out of 208 patients who's parents were preconsented were subsequently enrolled in the trial, constituting only $3 \%$ of the 310 patients enrolled in the trial [32]. A further 158 parents chose to place their child on the opt out list [32]. In a qualitative study of paediatric cardiac arrest in a paediatric intensive care unit (PICU) setting, pre-consent was perceived as an excessive burden to parents and the validity of consent in this situation was questioned by the authors, as parents may have presumed the study details were not applicable to them at the time of consent, and therefore did not consider the implications adequately [19].

In circumstances where consent is delayed, meaning that the intervention is commenced without consent, but consent sought later to continue with the trial and for the use of data, the timing of approaching parents with trial information is important. Such studies have been variably described as delayed, deferred or retrospective consent. Nine studies specifically used the term "deferred consent" [20-23, 25, 27-29, 31]. Four studies discussed implications concerning the timing of approach for consent when retrospective or deferred consent processes are used [22, 23, 27, 28]. Generally, across parents and practitioners there is agreement that approach for consent in these circumstances should occur once the child's condition is perceived to be stabilised [22, 23, 27, 28]. Both practitioners and parents expressed views that the timing of the approach, could affect the likelihood of agreeing [22, 23].

\section{Modified or limited consent process}

While acknowledging the difficulties of obtaining prospective informed consent in a number of studies, participants often preferred "some consent" rather than enrolment with no information at all [19, 21, 25]. The suggested modified consent usually took the form of brief verbal consent, or "assent" of parents at enrolment $[19,21,25]$. A study of the views parents of children admitted to a PICU about a deferred consent project, found they thought the process was only acceptable if there was some information provided at enrolment [25]. In a study that utilised both full prospective informed consent (when possible) and "assent" in other circumstances, consisting of a single paragraph briefly explaining the trial being read to participants. About half of participants were enrolled with each process overall, however the proportions varied between sites, suggesting physician preference and comfort with procedures, rather than only participant and parent factors influenced the type of consent used [21]. Only $0.4 \%$ who assented withdrew consent later. Staff generally supported the process in this setting, however some questioned the 
validity of assent in these circumstances or thought it too might delay treatment [21].

\section{Exploring issues of child death during the research}

Six studies reported relevant data regarding the situation of child death during research and use of alternatives to prospective informed consent. Issues included whether seeking consent was appropriate, whether consent should be waived in this circumstance and the need to balance the additional burden of disclosure to parents against their right to be informed [27, 28].

Studies of parental opinion regarding the disclosure of participation in research and deferred consent being sought in the case of child death during a trial have found mixed results $[27,28]$. Some data suggest the majority of parents favour disclosure, and altruism in that the data could contribute to the greater good, usually stated as a reason [23, 27, 28]. However, contrasting views were also apparent with some parents strongly favouring non-disclosure in this situation [28]. Gamble et al. explored and compared attitudes of bereaved and non-bereaved parents and suggests attitudes were different, with the majority (66\%) of bereaved parents favouring disclosure contrasting with $57 \%$ of non-bereaved parents expressing a preference for non-disclosure. Preference for non-disclosure was usually to avoid causing additional distress to grieving parents [27].

Two studies reported data from the $\mathrm{CATCH}$ trial, where children were enrolled in both emergency and elective settings [20, 23]. Of children enrolled in an emergency setting consent was obtained for only 984/ 1358 (72\%) because of lack of opportunity or because staff decided not to approach parents. Consent was refused for 26 children who died and 151 who survived, but the reasons for refusal differed between groups. The mortality rate of consented children was $9 \%$, compared to $18 \%$ for non-consented children, whose data were excluded from analysis [20]. A qualitative evaluation of this trial including bereaved parents, found some were "shocked" that their children had been enrolled in research without prior consent [23]. Others described experiences where they thought the manner of approach had been insensitive. Doctors felt that approach after death was far more challenging [23], and clinicians frequently opted to not approach grieving families [20]. A contrasting method was adopted by investigators (and ethics committees) of the FEAST study, who deemed it "unethical" to approach parents when a child died, and included data for patients who provided assent and waived the requirement for informed, deferred consent [21]. Opinions varied in relation to the most appropriate time to approach parents for consent in the case of child death during a trial. Mostly, data suggest that approaching bereaved parents for consent should "not be too soon" and advocating clinician discretion [27, 28]. Children reportedly understood the potential for bias with refusal of parental consent in a deferred consent study [29].

\section{Discussion}

Our systematic review of stakeholder attitudes to alternatives to prospective informed consent in paediatric emergency medicine found the limited available evidence suggested that children, families and practitioners were aware of the limitations of prospective informed consent for emergency and time critical research, were generally supportive and seemed to acknowledge the requirement for alternative strategies. Identified barriers to informed consent included the capacity of parents, insufficient time (compared to therapeutic windows of interventions), and some process issues like paperwork. Modifications to some processes were proposed.

The diminished capacity of parents to consent under stressful circumstances should not be surprising. Even under ideal circumstances research participants are often demonstrated to have suboptimal understanding [33, 34]. Similarly, in emergency surgery situations the validity of consent for clinical care has been questioned due to poor retention of information [35]. In the research context a concept of the "therapeutic misconception" is a common theme, where it is not clear whether parents can accurately differentiate consent for clinical care and research participation.

The terminology used in studies with research without prospective informed consent differed between studies and international variation was apparent. Some authors have criticised terms such as "deferred", "delayed" or "retrospective" consent, and contend that consent is not possible after the fact, and contravenes the principle of respect for autonomy [1, 36]. However international guidance documents highlight the requirement for research when consent is not possible, and the importance of discussing the research with the patient or surrogate decision maker as soon as possible in such circumstances $[4,10]$. The term deferred consent has been used in the medical literature since the 1990s, and tends to refer to permission to continue in the study, or if the study intervention has ended, permission to use the data [1]. Legislation was specifically introduced in Europe and the UK to allow much needed research to occur in situations where obtaining prior informed consent was not possible, which was identified as a problem under the previous legislative arrangements. The USA has similar legislation, where research needs to meet requirements for the federal "exception from informed consent" [12]. In our review, nine of the included studies specifically addressed, and used the term "deferred consent", meaning it was the most commonly evaluated strategy when prospective informed consent was not 
possible $[20-23,25,27-29,31]$. In the Australian context, while the NHMRC National Statement does not specifically use the term deferred consent, section 4.4.14 reinforces the process of informing participants, with the statement "As soon as reasonably possible, the participant and/or the participant's relatives and authorised representatives should be informed of the participants inclusion in the research and the option to withdraw from it without any reduction in quality of care" [4]. This seems to refer to and seek to achieve similar objectives as a deferred consent process.

While research evaluating alternatives to prospective informed consent has been performed in adults, there is relatively few studies in the paediatric setting. We hypothesized that parents and the general community may be less inclined to support research of this type in children, however the majority of people recognised the need for this research to occur, and supported the requirement for research without prospective informed consent, which was similar to previous adult studies [5]. A major limiting factor was the "situational incapacity" of parents precluding valid consent even if immediately available, and limited time for valid prospective informed consent in many situations.

Alternative strategies were proposed that included the opportunity to consent prior to meeting inclusion criteria, the option to "opt out" at the time of enrolment and versions of a modified consent process [19, 21, 25]. Prior consent is seldom a viable option for emergency research, as prior identification of potentially eligible patients is often not feasible, and efforts for prior consent are usually prohibitively inefficient, and may result in selection bias. In emergency trials, particularly in paediatrics the target population is not easily identified in advance. Community consultation efforts in the USA have often included an "opt out" option for clinical trials conducted under the exception to informed consent legislation, but again the process is inefficient, and difficult to implement, with few patients excluded on this basis $[26,32]$. An alternative that may not be applicable in all circumstances is the middle ground, of including a brief verbal consent or "assent" process, prior to enrolment in a trial [21]. In extremely time critical interventions, such as cardiac arrest, delays of just minutes may cause harm, therefore this approach would not be useful, but in other circumstances it may be a viable option and fulfil the parents desire to be involved in decision making, reduce some processes of informed consent like paperwork, focus more on managing the child and importantly given the opportunity to decline participation prior to enrolment.

\section{Limitations}

Our review had a number of limitations. Firstly there is no consensus on how to assess quality in qualitative research, or the utility of such an assessment [37]. Over 100-quality assessment tools have been proposed and used for the purposes of critical appraisal of qualitative studies and several are in relatively common use [38]. We used the Qualitative Assessment and Review Instrument (QARI) from the Joanna Briggs Institute [18], which has been widely used for this purpose, and no studies were excluded on the basis of quality assessment, and no studies were deemed to be of low quality. Abstracts were included in the review, which did not contain sufficient information to allow formal quality assessment. It should be recognised that this review identified only 13 studies, which limits the conclusions that can be made. In particular, data on the perspectives of children were lacking. Implications and conclusions for our setting are also hampered by the absence of any Australian studies. Most included studies were from the USA or UK, which may be somewhat applicable in the Australian context due to a degree of similarity with health systems, societal norms and shared values.

\section{Conclusion}

In conclusion, our systematic review of attitudes of stakeholders on alternatives to prospective informed consent in paediatric emergency research demonstrated that children, their families, health care staff, institutions, and the community seem to recognise the requirement for research performed without prior consent, and are generally supportive of enrolling children in such research with the provisions of limiting the degree of risk, and informing parents and/or children as soon as possible. There is a noted lack of Australian data as well as an insufficient understanding of the perspectives of children; both areas represent important knowledge gaps that need to be addressed through high quality research. Giving patients and their families a voice in discussions of alternatives to informed consent in emergency and critical care research in children, and greater engagement in the design of studies is necessary to maintain the trust of the community, and allow vital research to continue.

\section{Additional file}

Additional file 1: Medline (Ovid) search. (DOCX 109 kb)

\section{Abbreviations}

ED: Emergency departments; IRB: Institutional review boards; NHMRC: National Health and Medical Research Council; PECARN: Pediatric Emergency Care Applied Research Network; PICU: Paediatric intensive care unit; UK: United Kingdom; USA: United States of America

\section{Acknowledgements}

The authors would like to acknowledge the support of the Emergency Medicine Foundation (EMF) and the Townsville Hospital Study, Education and Research Trust Account (SERTA). Dr. Furyk is partly supported by a scholarship from the EMF and PREDICT. 


\section{Funding}

There was no specific funding for this research.

\section{Availability of data and materials}

The corresponding author will make data available on request.

\section{Authors' contributions}

JF, KM and RR conceived the study, all authors assisted with drafting the protocol, JF, KM and RR performed the literature search, applied inclusion criteria, data extraction and quality assessment. JF, KM, BR, KW, RF, TE, RR, FB and SD contributed to interpretation of the data and drafting of the manuscript. JF, KM, BR, KW, RF, TE, RR, FB and SD approved of the final manuscript.

\section{Ethics approval and consent to participate}

Ethics approval and individual participant consent was not sought for this systematic review.

\section{Consent for publication \\ None}

\section{Competing interests}

The authors declare that they have no competing interests.

\section{Publisher's Note}

Springer Nature remains neutral with regard to jurisdictional claims in published maps and institutional affiliations.

\section{Author details}

${ }^{1}$ College of Public Health, Medical and Veterinary Sciences, James Cook University, Townsville, QLD 4814, Australia. ${ }^{2}$ University Hospital Geelong, Geelong, Victoria, Australia. ${ }^{3}$ Townsville Health Library, Townsville Hospital and Health Service, James Cook University, Townsville, QLD, Australia. ${ }^{4}$ Research Methods \& Injury Epidemiology, College of Public Health, Medical and Veterinary Science, James Cook University, QLD, Townsville 4811, Australia. ${ }^{5}$ College Medicine and Dentistry, James Cook University, Townsville, QLD, Australia. ${ }^{6}$ Emergency Department, Royal Children's Hospital, Melbourne, 50 Flemington Rd, Parkville, VIC 3052, Australia. ${ }^{7}$ Murdoch Children's Research Institute, Melbourne, 50 Flemington Rd, Parkville, VIC 3052, Australia. ${ }^{8}$ Department of Paediatrics, Faculty of Medicine, Dentistry and Health Sciences, University of Melbourne, Melbourne, Grattan St, Parkville, VIC 3010, Australia. ' $E$ Emergency Medicine Research, Children's Emergency Department, Starship Children's Hospital, Auckland District Health Board, Private Bag 92024, Auckland 1142, New Zealand.

Received: 12 June 2018 Accepted: 25 October 2018 Published online: 20 November 2018

\section{References}

1. Brierley J, Larcher V. Emergency research in children: options for ethical recruitment. J Med Ethics. 2011;37(7):429-32 PubMed PMID: 21345861. Epub 2011/02/25. eng.

2. Furyk JS, Lawton LD, Ting JY, McD Taylor D. Informed consent in emergency care research: an oxymoron? Emerg Med Australas. 2017;29(1): $110-2$.

3. Advanced Paediatric Life Support. In: Samuels M, Wieteska S, editors. A practical approach to emergencies. Chichester, West Sussex: Wiley; 2016.

4. NHMRC. National Statement on ethical conduct in human research (2007) updated May 2015. Canberra: National Health and Medical Research Council; 2007.

5. Lecouturier J, Rodgers H, Ford GA, Rapley T, Stobbart L, Louw SJ, et al. Clinical research without consent in adults in the emergency setting: a review of patient and public views. BMC Med Ethics. 2008;9:9 PubMed PMID: 18445261. Pubmed Central PMCID: PMC2390563. Epub 2008/05/01. eng.

6. National Ethics Advisory Committee. Ethical guidelines for intervention studies. Wellington, New Zealand: Ministry of Health; 2009.

7. Biros M, Lewis RJ, Olson C, Runge JW, Cummins R, Fost N. Informed consent in emergency research. JAMA. 1995;273(16):1283-7.

8. Chamberlain JM, Lillis K, Vance C, Brown KM, Fawumi O, Nichols S, et al. Perceived challenges to obtaining informed consent for a time-sensitive emergency department study of pediatric status epilepticus: results of two focus groups. Acad Emerg Med Off J Soc Acad Emerg Med. 2009;16(8):76370 PubMed PMID: 19673713. Epub 2009/08/14. eng.

9. CRASH. Research in emergency situations: with or without relatives consent. Emerg Med J. 2004; Nov;21(6):703. PubMed PMID: 15496698. Pubmed Central PMCID: PMC1726499. Epub 2004/10/22. eng.

10. Association WM. World medical association declaration of Helsinki: ethical principles for medical research involving human subjects. JAMA. 2013; 310(20):2191-4.

11. United Kingdom Government. Medications for Human use (Clinical Trials) Amendments (No. 2). 2006.

12. 21 CFR 50.24 and 45 CFR 46.101(i) (1996). Protection of human subjects; informed consent, and waiver of informed consent requirements in certain emergency research; final rules. Fed Reg. 1996;61(192, Oct 2):51498-533.

13. Gray JD. The problem of consent in emergency medicine research. CJEM. 2001;3(3):213-8 PubMed PMID: 17610787. Epub 2007/07/06. eng.

14. Moher D, Liberati A, Tetzlaff J, Altman DG, PRISMA Group. Preferred Reporting Items for Systematic Reviews and Meta-Analyses: The PRISMA Statement. Plos Med. 2009;6(7):e1000097.

15. Thomas J, Harden A. Methods for the thematic synthesis of qualitative research in systematic reviews. BMC Med Res Methodol. 2008;8:45.

16. Ring N RK, Mandava $L$, Jepson R.. A guide to synthesising qualitative research for researchers undertaking health technology assessments and systematic reviews. 2010 [cited 2016 August 20]. Available from: http:// www.healthcareimprovementscotland.org/previous_resources/hta_report/ synthesising_research.aspx.

17. Quality Assessment Tool for Observational Cohort and Cross-Sectional Studies. United States,: Department of Health and Human Services, National Heart, Lung, and Blood Institute; [cited 201621 Dec]. Available from: www.nhlbi.nih.gov/ health-pro/guidelines/in-develop/cardiovascular-risk-reduction/tools/cohort.

18. The-Joanna-Brigs-Institute. Joanna Briggs Institute Reviewers Manual. 2014th ed; 2014.

19. Morris MC, Nadkarni VM, Ward FR, Nelson RM. Exception from informed consent for pediatric resuscitation research: community consultation for a trial of brain cooling after in-hospital cardiac arrest. Pediatrics. 2004;114(3): 776-81.

20. Harron K, Woolfall K, Dwan K, Gamble C, Mok Q, Ramnarayan P, et al. Deferred Consent for Randomized Controlled Trials in Emergency Care Settings. Pediatrics. 2015;136(5):e1316-22.

21. Molyneux S, Njue M, Mwanamvua Boga, Akello L, Olupot-Olupot P, Engoru C, et al. 'The Words Will Pass with the Blowing Wind': Staff and Parent Views of the Deferred Consent Process, with Prior Assent, Used in an Emergency Fluids Trial in Two African Hospitals. PLoS One. 2013;8(2).

22. Woolfall K, Frith L, Gamble C, Young B. How experience makes a difference: practitioners' views on the use of deferred consent in paediatric and neonatal emergency care trials. BMC Med Ethics. 2013;14(45).

23. Woolfall K, Frith L, Young B. P07 Evidence-based guidance to inform consent seeking in children's critical care trials. Arch Dis Child. 2015;100:A3-4.

24. Stanley RM, Johnson MD, Vance C, Bajaj L, Babcock L, Atabaki S, et al. Challenges Enrolling Children Into Traumatic Brain Injury Trials: An Observational Study. Acad Emerg Med. 201701 Jan;24(1):31-39. PubMed PMID: 614067905. English.

25. Menzies J, Callens C, Agrawal S, Whitehouse W. Consumer involvement in the design of a refractory status epilepticus trial in children. Pediatr Crit Care Med. 2011 May;1):A120. PubMed PMID: 70418967. English.

26. Bulger EM, Schmidt TA, Cook AJ, Brasel KJ, Griffiths DE, Kudenchuk PJ, et al. The random dialing survey as a tool for community consultation for research involving the emergency medicine exception from informed consent. Ann Emerg Med. 2009;53(3):341-50.

27. Gamble C, Nadel S, Snape D, McKay A, Hickey H, Williamson P, et al. What parents of children who have received emergency care think about deferring consent in randomised trials of emergency treatments: postal survey. PLoS One. 2012;7(5):e35982 PubMed PMID: 22586456. Pubmed Central PMCID: 3346812.

28. Woolfall K, Young B, Frith L, Appleton R, lyer A, Messahel S, et al. Doing challenging research studies in a patient-centred way: a qualitative study to inform a randomised controlled trial in the paediatric emergency care setting. BMJ Open. 2014;4(5):e005045 PubMed PMID: 24833694. Pubmed Central PMCID: 4025463

29. Scholefield B, Gosney J, Callens C, Duncan H, Morris K, Draper H. Consultation with children regarding deferred consent in emergency care research. Pediatr Crit Care Med. 2011 May;1):A44. PubMed PMID: 70418568. English. 
30. Woolfall K, Roper L, Sherratt F, McNamara P, Appleton R, Crawley E, et al. Children and young people support research without prior consent in life threatening situations: a qualitative study. Eur J Pediatr. 2016;175(11):1525-6

31. Scholefield BR, Lyttle MD, Berry K, Duncan HP, Morris KP. Survey of the use of therapeutic hypothermia after cardiac arrest in UK paediatric emergency departments. Emerg Med J. 2013;30(1):24-7 PubMed PMID: 22389354. English.

32. Holsti M, Zemek R, Baren J, Stanley RM, Mahajan P, Vance C, et al. Variation of community consultation and public disclosure for a pediatric multicentered "Exception from Informed Consent". Clin Trials. 2015;12(1):67 PubMed PMID: 25369796. Pubmed Central PMCID: NIHMS631494. English.

33. Yuval R, Halon DA, Merdler A, Khader N, Karkabi B, Uziel K, et al. Double comprehension and reaction to participating in a double blind randomized clinical trial (ISIS-4) in acute myocardial infarction. Arch Intern Med. 2000; 160:1142-6.

34. Flory J, Emanuel E. Interventions to improve research participants' understanding in informed consent for research. A Systematic Review. JAMA. 2004;292(13):1593-601.

35. Li FX, Nah SA, Low Y. Informed consent for emergency surgery--how much do parents truly remember? J Pediatr Surg. 2014;49(5):795-7 PubMed PMID: 24851773. English.

36. Johnson LR, Siddaiah R. Use of deferred consent for enrolment in trials is fraught with problems. BMJ. 2015;351:h4609 PubMed PMID: 26330402.

37. Carroll C, Booth A. Quality assessment of qualitative evidence for systematic review and synthesis: is it meaningful, and if so, how should it be performed? Res Synth Methods. 2015;6(2):149-54 PubMed PMID: 26099483.

38. Higgins J GS. Cochrane Handbook for Systematic Reviews of Interventions Version 5.1.0 [updated March 2011 1]. Available from http://www.cochranehandbook.org.: 2011 [[cited 2016 August 25].].

39. Rademacher NJ, Clark SJ, Davis, MM, Al-Lawati, Z, Stanley, R. Parental attitudes towards the use of the federal exception from informed consent (EFIC) for emergency studies of severe traumatic brain injuries. Acad Emerg Med. Vol1. S192-S193 (Abstract)

Ready to submit your research? Choose BMC and benefit from:

- fast, convenient online submission

- thorough peer review by experienced researchers in your field

- rapid publication on acceptance

- support for research data, including large and complex data types

- gold Open Access which fosters wider collaboration and increased citations

- maximum visibility for your research: over $100 \mathrm{M}$ website views per year

At $\mathrm{BMC}$, research is always in progress.

Learn more biomedcentral.com/submissions 